“( 2016 IEEE. Personal use of this material is permitted. Permission from IEEE must be obtained for all other uses, in any current or future media, including

reprinting/republishing this material for advertising or promotional purposes, creating new collective works, for resale or redistribution to servers or lists, or reuse of any copyrighted component of this work in other works." 


\section{Designing a Personal Information Transaction Object}

\author{
Ross Farrelly \\ University of Technology, Sydney \\ ross.w.farrelly@student.uts.edu.au
}

\begin{abstract}
As mobile and wearable technologies grow in popularity, ever-increasing volumes of valuable, finegrained personal information are generated as people go about their daily lives. This information may be exchanged by individuals for "free" services, but there is currently no widely adopted means by which individuals can benefit financially from their personal information. To address this problem we consider a Primary Personal Information Market (PPIM) - a market on which individuals can be financially compensated in exchange for access to their personal information. We draw on Design Science and Market Engineering to justify design choices for a permissions-based Personal Information Transaction Object (PITO), a commodity which could be successfully traded on a Primary Personal Information Market.
\end{abstract}

\section{Introduction}

There is a growing recognition that the personal information generated by individuals as they go about their daily lives embodies significant economic value [2]. These data allow companies to identify and develop niche markets [3] and to personalise products and services [4]. The potential economic impact of digital identities in the coming decades in the European economy alone has been estimated at $€ 330$ billion annually for organisations and $€ 670$ billion annually for individuals [5].

The value of this personal information is further demonstrated by the thriving secondary market in personal information, in which companies collect personal information, and on-sell it in a variety of ways [6]. However, this secondary market is opaque and operates without the explicit consent of the individuals who generated the data [7].

This research-in-progress paper is written in the context of a broader research project to design and develop a Primary Personal Information Market (PPIM) [1] to address these problems. The research question we seek to address is: how should a Personal Information Transaction Object (PITO) be designed in order to ensure that the PPIM on which it is traded is of high quality?

\author{
Eng Chew \\ University of Technology, Sydney \\ eng.chew@uts.edu.au
}

In this paper we draw on Design Science $[8,9]$ and Market Engineering theory [10] to identify relevant measures of market quality which constitute the design criteria for a PITO and to compare design alternatives for a PITO against these measures (design criteria)

Design Science is the preferred methodology because it is suited to the rigorous design of relevant new artefacts [11]. Design Science has been utilised to address a range of related design challenges such as evaluating electronic market designs [11] and efficient pricing in the electricity retail market [12].

While Design Science is a generic design methodology which can be applied to a wide range of problems, there is a need for an additional theory to address the particular design challenges of a PPIM, particularly in the atomisation phase of Design Science. Atomisation is the process of identifying sub-components of a larger problem to better understand its complexity [9]. We draw on Market Engineering theory to identify sub-components of the PPIM.

Market Engineering is our preferred methodology because it is concerned with the "conscious and structured design of ...[markets]... to be implemented in computer systems" [10:3], which is the task we are engaged in. Market Engineering has been employed in designing a wide range of markets, such as markets for e-health services [13] and resource allocation in computational grids [14].

This paper is relevant because of the ubiquity of personal data and the growing recognition that personal data are valuable, but that individuals do not receive financial benefits from their data [15].

It is relevant to individuals who are concerned about what happens to their personal data and who are concerned about equity in the online environment. It is also relevant to researchers who study online markets, information markets and market design.

This paper makes a contribution to the literature by testing whether the concept of permission-based PITO traded on a PPIM has prima facie feasibility, a necessary contribution to justify further research in on the subject.

This paper is organised as follows. In Section 2 we present related research, briefly describe a PPIM and outline the justification for designing such a market. In Section 3 we locate our design approach in the Design Science and Market Engineering 
disciplines and outline our method. We outline the criteria against which design choices for a PITO will be measured in Section 4. In Section 5 we canvass the PITO design alternatives and assess each alternative against the PITO design criteria. In Section 6 we describe the proposed PITO design solution and in Section 7 we present the results of the evaluation of our PITO design. In Section 8 we conclude and finally outline areas for further research in Section 9.

\section{Background}

The references in this section was were sourced using a process similar to Kitchenham's systematic literature review methodology [16] by searching Business Source Complete, ACM Digital Library, IEEE Explore, ProQuest and Scopus for the phrases "market engineering", "market design", "market quality measures", "market components", "knowledge market design" and "online marketplace design".

A Primary Personal Information Market (PPIM) is a market in which the original producer of personal information, also referred to as the data subject, sells access to that information in some way to a consumer who wishes to benefit from access to that information. When ownership of the data is granted the resulting market is an ownership-based PPIM, when permission-to-use the personal data is granted it is a permission-based PPIM. These primary markets stand in contrast to a secondary market in personal information in which the original producer of the personal information is not a direct participant.

Anonymous [1] makes the case for a PPIM. They argue that with recent developments in mobile and wearable technology, the volume and granularity of personal information is rapidly increasing. Furthermore, they observe that this personal information is valuable to companies. They cite as evidence for this the thriving secondary market in personal information.

From these premises they argue that there is an opportunity and need to develop a PPIM, a systems architecture for which is presented in Figure 1. The PPIM is based on a capture-at-source distributed synchronisation system. As an individual creates personal information on a device, a locally installed app captures and stores the personal information on the device (1). Once the device is connected to the central data repository, personal information is synchronised (2). The central data source (3) is structured around a logical data model (4). Management of the personal information permissions is facilitated by two dashboards - one for individuals (5) and one for companies (6).

One important element of any market design project is the design of the transaction object [17] the object which is to be bought and sold on the market. A market cannot operate if there is no transaction object. Furthermore, defining the transaction object is critically important because for a market to operate there must be market thickness, defined as the ability of a market to "attract a large enough proportion of the potential participants" [18: 79] and thickness in a market is influenced by the design of the transaction object [17].

There is an extensive body of research into areas which are relevant to the design of a workable PPIM such as: data ownership $[19,20]$ and privacy $[21,22]$, personal informatics [23, 24], the collection and modelling of personal information $[25,26]$ and data security $[27,28]$. However "there is a substantial lack of empirical research on ... markets for online personal data" [29] and most market design research is qualitative [30].

Spiekermann and Novotny [31] studied the research question of how individuals can share more personal information with companies while maintaining their personal privacy. They proposed a four-space model of personal information management by focusing on the type of relationship

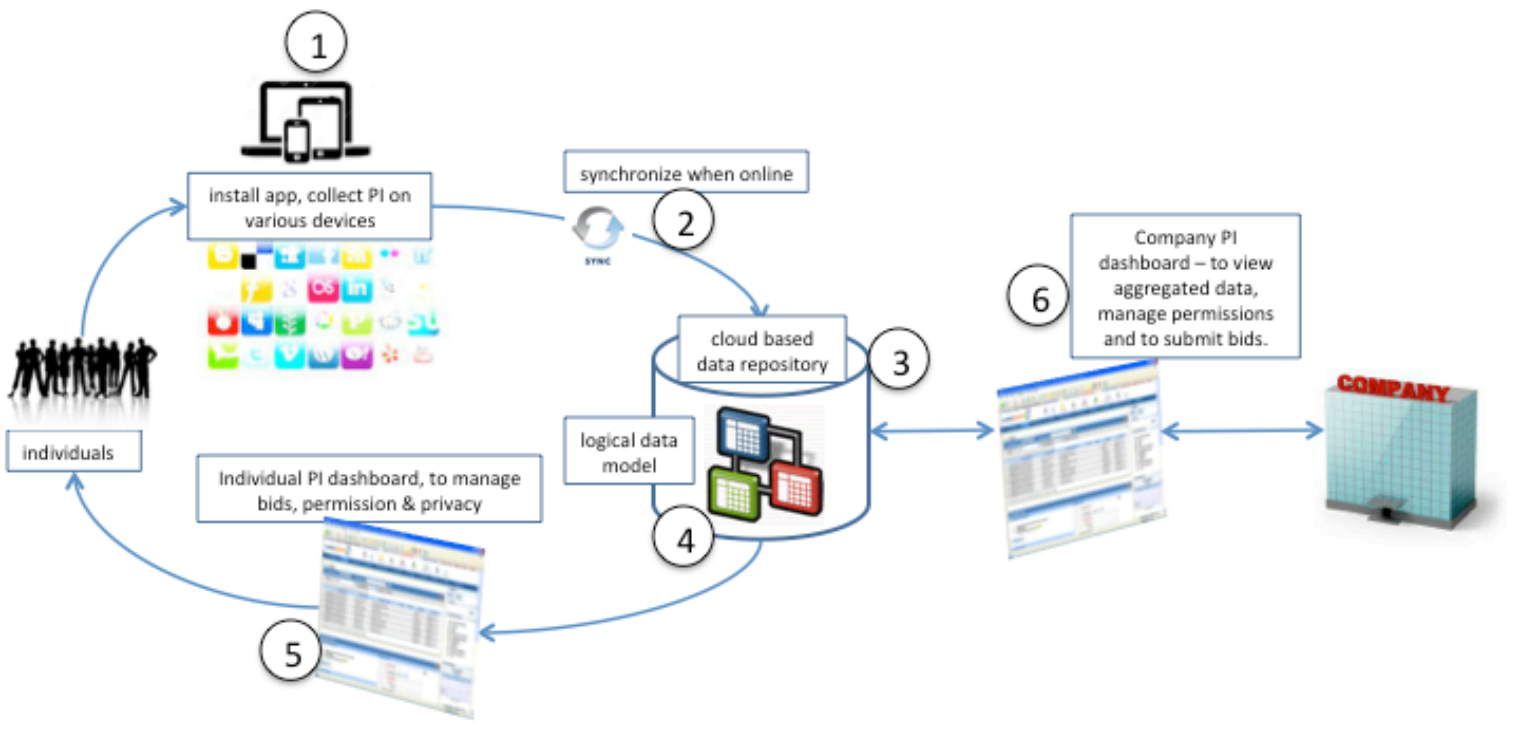

Figure 1. A system architecture for a PPIM [1] 
which exists between the individual and the company.

Aperjis and Huberman [32] proposed compensating individuals for allowing their data to be included in a sample from which the buyer sought to infer a statistic of interest about a population and Mashhadi et al [19] propose a data market for the trading of sensor data generated by the Internet of Things.

A close reading of these papers shows that very little justification is given for the design choices made in the personal information markets which have been proposed by other researchers.

Other researchers have alluded to the need for a marketplace for personal information - without explicitly calling for a PPIM. For instance de Montjoye et al [33] argue for the need for individuals to retain ownership of their personal information and for the establishment of a "fair and efficient market" in personal information. de Montjoye et al [34] argue that personal information stores will facilitate an "economically efficient" personal information market.

Zannier [35] tested the concept of selling his personal information. He collected detailed data on many aspects of his personal life and sold those data in exchange for contributions to his kick-starter project. He raised \$2,734 USD from 213 backers.

Sevignani [36] points out the need for individuals to have more control over their privacy while Milyaeva and Neyland [29] take a Science and Technology Studies approach and identify a growing trend in a number of recent start-ups which focus on the value of data usage rather than the value of data itself.

In summary, there is a growing body of research which testifies to the value of personal information, to the abundance and ubiquity of personal information, to the need for protecting privacy and to shortcomings in current personal information market practices. Research into the design of a PITO which can be traded on a PPIM as a means to addressing these issues is not yet available. This paper proposes and evaluates such a new PITO design.

\section{Method}

Since the design of PITO, a new artefact, is an integral part of the design of PPIM, another new (parent) artefact, we follow the Design Science methodology $[8,9,37]$. The atomisation stage of the Design Science process [9] is achieved by drawing on Market Engineering theory [38], a well-recognised research approach to the design of markets - see [13] for example.

This paper seeks to clarify the nature of the transaction object which is bought and sold in the PPIM. To do so we identify key drivers of market efficiency and assess the impact that the alternative PITO design decision will have on these drivers.

We evaluate the market-engineering based PITO design qualitatively [39] using semi-structured interviews. These interviews were conducted with senior leaders in data related business roles, who were selected on the basis of their subject matter expertise [57]. This is consistent with other studies; see for example [40, 41].

The aim of the evaluation was to gather opinions from interviewees on the following key implementation factors: the feasibility of building a PPIM for trading permission-based PITOs, the viability of such a PPIM if it were to be built, the relative merits of a permission-based PITO versus an ownership-based PITO, and the appetite companies and individuals might have to participate in such a PPIM.

The selection of interviewees was guided by theoretical sampling [42] in which we sampled experts who could evaluate the constructs and structure of the proposed designs based on their domain expertise and years of experience (as indicated by the subjects' LinkedIn profiles). Some interviewees recommended other suitable subjects with applicable knowledge which led to clustered samples [43].

Interviewees included representatives in senior analytical roles from academia, government funded research organisations, a large Federal Government department, an Australian home loan brokerage company, and a major political campaign advisory company. On average, interviewees had 9.7 years of work experience in data related roles. The interviews were digitally recorded and transcribed. The interviews lasted on average 30 minutes.

An interview topic guide [44] was used for interview consistency. After a brief explanation of the purpose of the research and the proposed roles of PPIM, PITOS and PITO the interviewees were asked their opinions on the sensibility and feasibility of the proposed solutions. They were asked if they saw any major flaws or issues with the proposed solution. They were asked whether or not such a market would be viable, and based on their experience whether there was appetite for companies to purchase detailed personal information on such a market and the willingness of individuals to share personal information on such a market. The results of these interviews are summarised and analysed in Section 7.

\section{Design criteria}

In designing a Personal Information Transaction Object (PITO) we aim to make design choices which will improve the performance of the PPIM on which it is traded. Design choices are compared against market success criteria, for which there is an extensive body of research. Market quality has been 
described as "the extent to which a market satisfies its participants" [45]. Commonly identified characteristics of high quality markets are: thickness, low congestion, safety, simplicity, transparency, immediacy and low search and transaction costs $[18$, 45, 46]. They therefore represent the success criteria for a PITO design in a PPIM.

In order to design a working PPIM, we must design each element of the market so that it satisfies the needs of both companies who wish to access personal information and individuals who want to profit from sharing their personal information.

We use these characteristics as criteria to assess design alternative for the transaction object in a PPIM.

\section{Design parameters}

In this section we examine the crucial design decision of ownership versus permission to use, which must be made when designing a PITO. We then assess the alternatives in terms of the success criteria outlined in Section 4 and explore the preferred option in more detail.

The fundamental design decision to be made in a PITO is the question of ownership. Is the outright ownership of the personal information to be bought and sold, or does the ownership of the personal information remain with the individual who generated it in the first place?

Allowing the ownership of the personal information to remain with the individual is likely to contribute to market thickness because it will be more beneficial to individuals. For example, Schwartz [47:2056] argues that "limitations on an individual's right to alienate personal information" is a key aspect of successfully propertising personal information.

Furthermore, it is clear that companies can extract commercially valuable insights from personal information even when the ownership remains with the individual. The end user licence agreements of the major social network sites [48-50] attest to this.

Since retention of ownership of personal information is beneficial to both individuals and companies it will contribute favourably to thickness in the market as compared to the alternative design choice.

Allowing individuals to retain ownership of their personal information would also enhance safety. In a permission-based PPIM, individuals would have more control of the use to which their personal information was put.

A PPIM in which ownership was transferred from individual to company would be simpler than the alternative as the concept of ownership is a less nuanced concept than that of permission. However, allowing individuals to retain ownership of their personal information would enhance transparency.
By explicitly allowing or denying use of their personal information by certain companies, individuals would have a much clearer view of what was being traded on the PPIM. Spiekermann and Novotny [31] have shown that in the absence of these explicit permissions an opaque shadow market in personal information has emerged. A transparent regulation framework also encourages individuals to share their information, adding to thickness in the market [19].

The success factor of immediacy would not be significantly influenced by the design decision regarding ownership while the success criterion of search costs (from the perspective of companies searching for suitable permissions to fulfil their needs) would be negatively influenced by the added complexity of allowing individuals to retain ownership. Since permission is a multi-dimensional concept, the potential number of different products available on a permission-based PPIM is very large. Furthermore, the lack of a consistent language for describing permission could also contribute to additional search cost. The issue of search cost would be addressed by employing a consistent taxonomy of permissions.

In order to further clarify the proposed PITO it is necessary to define the permission which will be granted by the individuals to the company. We propose three main groups of descriptors: content, use and nature of the personal information.

The content of the personal information is described in terms of behaviour descriptors, identity descriptors and attributes [51]. Behaviours are descriptors such as travel, exercise and sleep patterns. Identity descriptors are descriptors of the datagenerating individual such as name, age, gender, etc. Attributes are annotations [52] associated with the personal information, such as intention and preference descriptors which can be extracted and derived from personal information. Also included in the content of the personal data is the date range over which the personal information will be retrieved. Additional content characteristics of the PITO are dependent on the way in which the personal information is modelled and the semantic extraction [53] of meaning from that information.

The use to which the personal information may be put includes the channels through which the individuals may be contacted (if at all) and the advertising channels through which the individuals may be marketed to (if any).

The nature of the personal information to which permission has been purchased is defined in terms of the concurrency of the permission: the maximum number of buyers which can simultaneously purchase access to that personal information. Clearly, exclusive access to personal information is more valuable than access which is shared with many other buyers. It also comprises the refresh frequency, the 
frequency at which the personal information will be refreshed. Personal information may be accessed at rates ranging from a one-off batch load through to a real time feed. Finally we define the tenure, the period of time after which the granted permission will expire.

\section{Privacy Meta-Parameters}

In addition to the design parameters described above, we propose a privacy meta-parameter. This acts a check and balance to inform the individual of the privacy implications of the permission he or she has granted. It can be used as a descriptive metric to measure the degree to which privacy has been exchanged or it can be used as a setting to indicate to an individual whether or not to exchange further permissions. The privacy setting is calculated using approaches such as k-anonymity [54], t-closeness [55], 1-diversity [56] and uniqueness of traces [57].

\begin{tabular}{|c|c|c|}
\hline & $\begin{array}{l}\text { Permission-based } \\
\text { PITO }\end{array}$ & $\begin{array}{l}\text { Ownership-based } \\
\text { PITO }\end{array}$ \\
\hline thickness & $\begin{array}{l}\text { higher - beneficial to } \\
\text { individuals and also } \\
\text { of utility to } \\
\text { businesses }\end{array}$ & $\begin{array}{l}\text { lower - more useful } \\
\text { to businesses but } \\
\text { less attractive to } \\
\text { individuals }\end{array}$ \\
\hline safety & $\begin{array}{l}\text { higher - enhanced by } \\
\text { transparency }\end{array}$ & $\begin{array}{l}\text { lower - individuals } \\
\text { loses control of PI }\end{array}$ \\
\hline simplicity & $\begin{array}{l}\text { lower more complex, } \\
\text { but manageable by a } \\
\text { well-designed } \\
\text { taxonomy }\end{array}$ & $\begin{array}{l}\text { higher-less } \\
\text { nuanced concept }\end{array}$ \\
\hline transparency & $\begin{array}{l}\text { higher - though } \\
\text { retaining ownership } \\
\text { of data }\end{array}$ & $\begin{array}{l}\text { lower - limited } \\
\text { visibility on how } \\
\text { data is used }\end{array}$ \\
\hline immediacy & similar & similar \\
\hline search costs & $\begin{array}{l}\text { higher - as concept is } \\
\text { more nuanced }\end{array}$ & $\begin{array}{l}\text { lower - as it is a } \\
\text { simpler concept }\end{array}$ \\
\hline transaction costs & similar & similar \\
\hline
\end{tabular}

\section{Proposed design solution}

\section{Personal Information Transaction Object Space (PITOS):}

From the design alternatives described in Section 5 above, we define the Personal Information Transaction Object Space (PITOS) as the set of all possible PITOs, i.e. the space from which individual PITOs can be drawn. More formally we define the PITOS as follows:

Let $n \in \mathbb{Z}^{+}$be a positive integer denoting the number of permissions, each permission being an agreement between the permission-granting individual and the purchasing company. Let $\mathrm{P}_{\mathrm{i}}, \mathrm{i} \in\{1 \ldots \mathrm{n}\}$ be the $\mathrm{i}^{\text {th }}$ permission in the PITOS. Let $n_{i} \in \mathbb{Z}^{+}, i \in\{1 \ldots n\}$ be the number of settings in the $i^{\text {th }}$ permission. Each permission comprises $n_{i}$ settings: $P_{i}=\left\{S_{i 1}, S_{i 2} \ldots S_{i_{i}}\right\}$ and the PITOS comprises the $n$ permissions $\left\{\mathrm{P}_{1}, \mathrm{P}_{2} \ldots \mathrm{P}_{\mathrm{n}}\right\}$.

Clearly the number of data sources and the number of uses to which the data could be put is extremely high and it would not be possible to know in advance the nature of the PITOs for which companies will have a need . To address this issue a highly developed Personal Information Logical Data Model (LDM) is required to facilitate the creation of a very wide range of PITOs. Furthermore, latebinding, schema-on-read elements to the personal data store will provide the flexibly for the system to respond by creating novel PITOs from semistructured data such as free text, XML and JSON data.

\section{Personal information transaction objects (PITO):}

A PITO is a single instance within the PITOS, defined by the setting of the design parameters.

For example, if an individual grants a company permission for two years to query against her Facebook data, contact her by SMS and to refresh that data every 12 hours, these permissions will comprise the PITO represented in Figure 2.

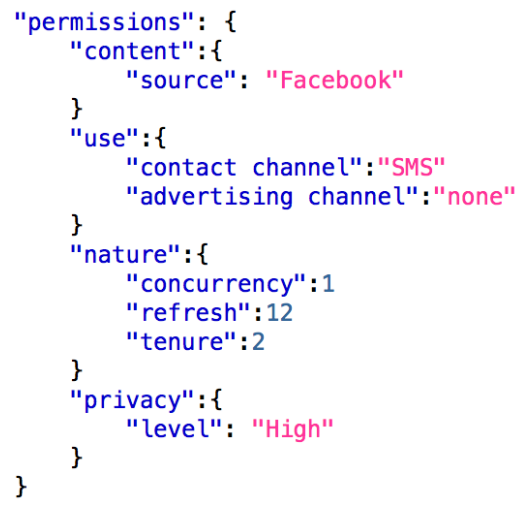

Figure 2: A Simplified PITO

The proposed permissions based PITOs would be created and traded on the PPIM as per. Figure 3.

1. Company browses the PITOS (as described in the LDM metadata).

2. Company conceives of a PITO and posts a description and price on the PPIM.

3. Individuals whose data could contribute to the PITO are identified in the data store.

4. Offers are sent to individuals.

5. Individuals accept or reject the offer.

6. If a sufficiently large number of individuals accept the offer, the PITO is created and exchanged on the PPIM. 


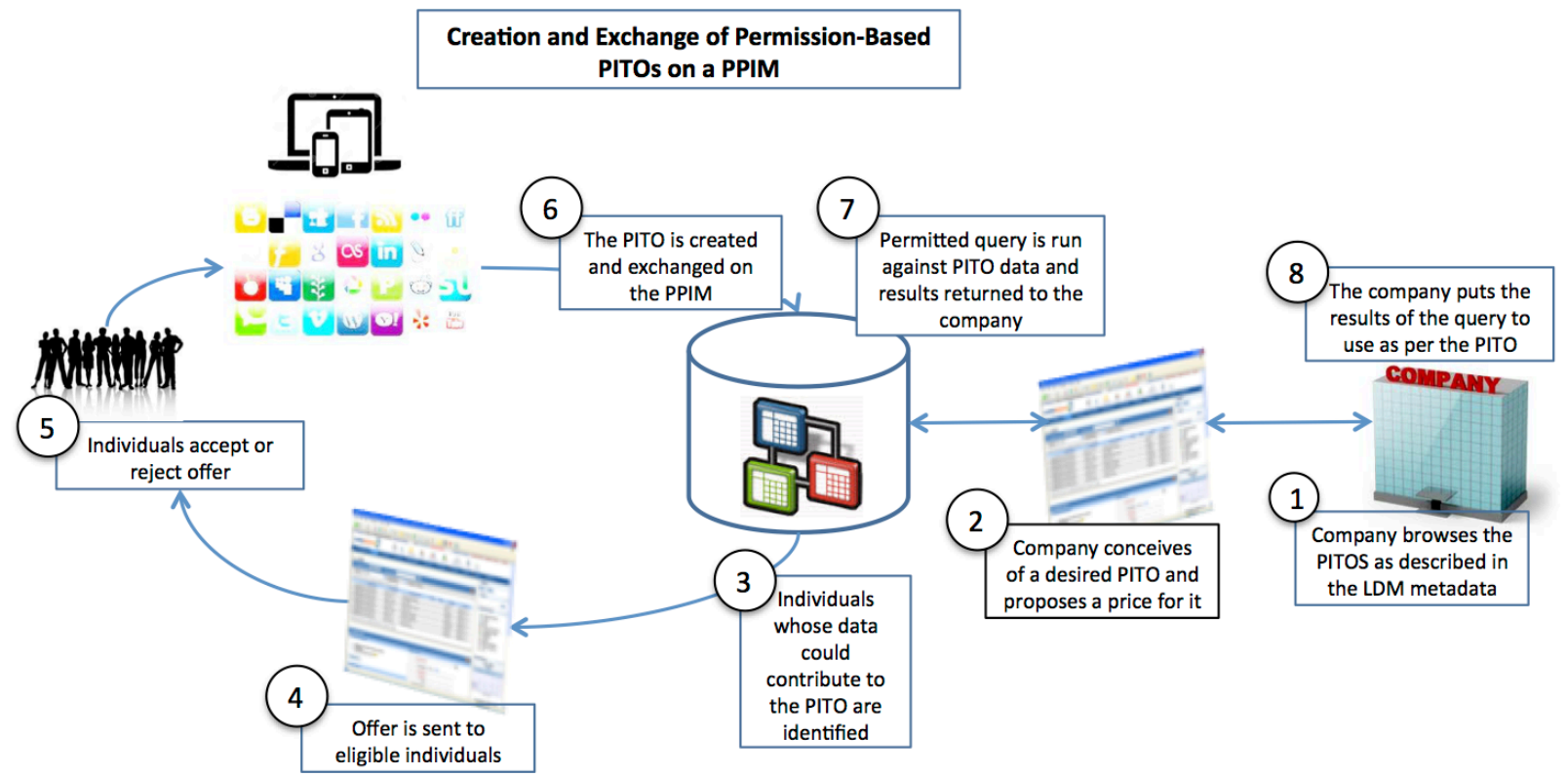

Figure 3: Creation and exchange of PITOs on a PPIM

7. The permitted query is run against the data which comprises the PITO and the results are returns to the company.

8. The company puts the results of the query to use as the permitted in the PITO via the PPIM.

\section{Evaluation}

Following Yin [39], we identify, compare and contrast the main themes in the interviewees' responses. TABLE 4 contains a classification of the interviewee's opinions with illustrative quotations.

Of the seven experts interviewed, five were of the opinion that permissions-based PPIM was, broadly speaking, viable.

Five of the seven respondents thought that there would be significant appetite from companies to purchase permission to query detailed personal information with two interviewees mentioning the imperative companies now have to gain a $360^{\circ}$ view of the customer. Only the expert from the political strategy advisory company was of the opinion that such a market would be of little interest to his industry. Three of the interviewees were of the opinion that individuals would be willing to sell permission to query personal information on the proposed market.

Interviewees were less emphatic on the question of a permission-based PITO versus an ownershipbased PITO with only four proffering an opinion. These opinions are summarised in TABLE 4.

There were three main issues raised by interviewees (see Table 3). The question of pricing access to personal information and how best to gain a critical mass in such a market were the most commonly raised objections. The use of proxy measures to infer information about individuals beyond the permission which has been granted was also raised as a concern.

Table 2: Summary of interviewees' opinions

\begin{tabular}{|l|l|l|l|}
\hline & Positive & Neutral & $\begin{array}{l}\text { No } \\
\text { opinion }\end{array}$ \\
\hline Viability & 5 & 1 & 1 \\
\hline $\begin{array}{l}\text { Permission vs. } \\
\text { ownership }\end{array}$ & 4 & 0 & 3 \\
\hline $\begin{array}{l}\text { Company } \\
\text { appetite }\end{array}$ & 5 & 1 & 1 \\
\hline $\begin{array}{l}\text { Individual } \\
\text { appetite }\end{array}$ & 3 & 1 & 3 \\
\hline
\end{tabular}

Table 3: Issues and concerns raised by interviewees

\begin{tabular}{|l|l|}
\hline Major Objections / Concerns & Count \\
\hline gaining a critical mass & 3 \\
\hline pricing & 3 \\
\hline use of proxy measures & 2 \\
\hline privacy & 1 \\
\hline
\end{tabular}

\section{Conclusion}

Following design science methodology [9, 10, $12,20]$ and qualitative interview methods $[22,57,58$, 59], this paper has respectively synthesised and qualitatively evaluated a design for a personal information transaction object (PITO) in accordance with the market design criteria espoused by Market Engineering theory [11] and extant market design practices $[19,41,42,55,56]$ so as to render our prior Primary Personal Information Market (PPIM) system-architectural design [1] technically feasible to implement. It proposes that a permission-based PITO 
TABLE 4: CLASSIFICATION OF OPINIONS AND ILLUSTRATIVE QUOTATIONS FROM INTERVIEWEES' RESPONSES

\begin{tabular}{|c|c|c|c|c|c|c|}
\hline Interviewee & & $\begin{array}{l}\text { Permission-based } \\
\text { PPIM viability }\end{array}$ & $\begin{array}{c}\text { Permission-based PITO } \\
\text { vs. ownership-based } \\
\text { PITO } \\
\end{array}$ & $\begin{array}{l}\text { Companies' appetite to } \\
\text { use a PPIM }\end{array}$ & $\begin{array}{l}\text { Individuals' appetite to } \\
\text { use a PPIM }\end{array}$ & objections / concerns \\
\hline \multirow{2}{*}{$\begin{array}{l}\text { Senior Director of } \\
\text { Analytics in large } \\
\text { Federal Government } \\
\text { Department }\end{array}$} & opinion & positive & none offered & positive & positive & proxy measures \\
\hline & $\begin{array}{l}\text { illustrative } \\
\text { quotes }\end{array}$ & "I think it's got merit" & N/A & $\begin{array}{l}\text { "understanding the } \\
\text { customer is probably the } \\
\text { primary driver of the work } \\
\text { in this organisation for the } \\
\text { next so many years" }\end{array}$ & $\begin{array}{l}\text { "I see a huge market for } \\
\text { it" }\end{array}$ & $\begin{array}{l}\text { "We're living in an era when you can use } \\
\text { proxy measures to measure what it is you } \\
\text { want to measure and therefore the public } \\
\text { will always, not always, most of them will } \\
\text { not know what it is exactly they are giving } \\
\text { away or could give away" }\end{array}$ \\
\hline \multirow{2}{*}{$\begin{array}{l}\text { Analytics Manager in } \\
\text { Government Agency }\end{array}$} & opinion & positive & positive & positive & neutral & critical mass \\
\hline & $\begin{array}{l}\text { illustrative } \\
\text { quotes }\end{array}$ & $\begin{array}{l}\text { "sounds quite viable" } \\
\text { and "... it's end to end } \\
\text { possible technically" }\end{array}$ & $\begin{array}{l}\text { "it seems rich, in possible } \\
\text { use cases..." }\end{array}$ & $\begin{array}{l}\text { "there's a demand for a lot } \\
\text { more existing companies } \\
\text { who have account holders, } \\
\text { but they don't know } \\
\text { enough about those } \\
\text { customers, and they would } \\
\text { love to be able to plug into } \\
\text { this resource" }\end{array}$ & $\begin{array}{l}\text { "I think that if you want } \\
\text { the network effect you } \\
\text { have to have a particular, } \\
\text { narrow applications space } \\
\text { where you can target } \\
\text { people" }\end{array}$ & $\begin{array}{l}\text { "I'm not sure whether the supply side can be } \\
\text { easily done" }\end{array}$ \\
\hline \multirow{2}{*}{$\begin{array}{l}\text { Chief Scientist in high } \\
\text { tech research } \\
\text { organisation }\end{array}$} & opinion & positive & none offered & positive & positive & pricing, critical mass, proxy measures \\
\hline & $\begin{array}{l}\text { illustrative } \\
\text { quotes }\end{array}$ & $\begin{array}{l}\text { "It's a truly important } \\
\text { question ... I think this } \\
\text { is absolutely } \\
\text { fantastic." }\end{array}$ & N/A & $\begin{array}{l}\text { "So in general my answer } \\
\text { to your question would be } \\
\text { yes if I was in a position to } \\
\text { be able to play into this } \\
\text { market" }\end{array}$ & $\begin{array}{l}\text { "The more they realise } \\
\text { the value of information } \\
\ldots \text { they may actually } \\
\text { enter the game" }\end{array}$ & $\begin{array}{l}\text { "you can for example identify ... very } \\
\text { intimate traits of people by simply looking at } \\
\text { traits that are not actually [that] sensitive" }\end{array}$ \\
\hline \multirow{2}{*}{$\begin{array}{l}\text { Senior Developer in an } \\
\text { Australian home loan } \\
\text { brokerage company }\end{array}$} & opinion & neutral & positive & positive & positive & pricing \\
\hline & $\begin{array}{l}\text { illustrative } \\
\text { quotes }\end{array}$ & $\begin{array}{l}\text { "It's in addition to } \\
\text { your primary, you } \\
\text { setup a secondary } \\
\text { market" }\end{array}$ & $\begin{array}{l}\text { it ... provides } \\
\text { transparency into what } \\
\text { you're giving away" }\end{array}$ & $\begin{array}{l}\text { "I do agree that the Holy } \\
\text { Grail for everyone is to } \\
\text { have that single stream [of } \\
\text { personal information]" }\end{array}$ & $\begin{array}{l}\text { "you're ... monetising } \\
\text { what you're giving away } \\
\text { for free" }\end{array}$ & $\begin{array}{l}\text { "it's the buyer who knows more about the } \\
\text { value [of the data] ... and the seller really is } \\
\text { at an absolute disadvantage as they have no } \\
\text { idea as to what ... benefits their personal } \\
\text { information can generate" }\end{array}$ \\
\hline \multirow{2}{*}{$\begin{array}{l}\text { Managing Director } \\
\text { major political } \\
\text { campaign advisory } \\
\text { company }\end{array}$} & opinion & none offered & none offered & neutral & none offered & none \\
\hline & $\begin{array}{l}\text { illustrative } \\
\text { quotes }\end{array}$ & N/A & $\mathrm{N} / \mathrm{A}$ & $\begin{array}{l}\text { "it would be a nice to have } \\
\text { rather than essential" }\end{array}$ & N/A & \\
\hline \multirow[t]{2}{*}{ Academic 1} & opinion & positive & positive & positive & none offered & raised alterative views on privacy \\
\hline & $\begin{array}{l}\text { illustrative } \\
\text { quotes }\end{array}$ & $\begin{array}{l}\text { "It sounds very } \\
\text { convincing" }\end{array}$ & $\begin{array}{l}\text { "As a person, I } \\
\text { completely agree with } \\
\text { you. I could not agree } \\
\text { more" }\end{array}$ & $\begin{array}{l}\text { "the market for personal } \\
\text { information is large and } \\
\text { booming" }\end{array}$ & N/A & $\begin{array}{l}\text { "[some people are] highly critical of the } \\
\text { idea of data vaults" }\end{array}$ \\
\hline \multirow[t]{2}{*}{ Academic 2} & opinion & positive & positive & none offered & none offered & pricing, critical mass \\
\hline & $\begin{array}{l}\text { illustrative } \\
\text { quotes }\end{array}$ & $\begin{array}{l}\text { "It's good to see } \\
\text {...workable } \\
\text { platforms. }\end{array}$ & $\begin{array}{l}\text { I find your model very } \\
\text { interesting." }\end{array}$ & N/A & N/A & $\begin{array}{l}\text { "what prices do you expect?" "how do you } \\
\text { get the individuals to actually contribute } \\
\text { the data to the marketplace?" }\end{array}$ \\
\hline
\end{tabular}


is preferable to an ownership-based PITO as it maintains personal privacy, enhances data transparency and promotes market thickness- the prerequisite conditions for viable commercialisation.

This paper reveals that the model proposed for a permission-based PITO and the resulting permission-based PPIM has the potential to be a viable approach to implementation and is therefore a worthwhile avenue of further research. A majority of the interviewed experts broadly agreed that there is a need for such a market and that if it could be designed and implemented there would be a potential high demand for such a market from a range of organisations.

This finding is significant, mainly due to the magnitude and wide ranging implications of the problem being addressed. A viable PITO (and the resulting PPIM) would potentially affect the lives of millions of individuals in a digitalised world and dramatically change the ways business utilises the value of personal information.

However, this study also shows that more research is needed into whether or not individuals would be willing to participate in a PPIM. It also highlights that a permission-based PITO is a complex and subtle issue which may need to be redesigned in order to make it more accessible to individuals and companies.

This paper has several limitations, as it is an initial investigation into the under-researched topic of PPIMs and their design. The evaluation was conducted on a very small number of experts and due to time constraints the interviews were somewhat brief. This study is being expanded and consolidated to reach more definitive conclusions and a proof-of-concept project to test the feasibility of this market in practice is being planned.

Despite these limitations, this paper shows that the subject is worth pursuing and points to a number of additional areas worthy of further research to enhance the potential for practical implementation of the PPIM, as described in the following section.

\section{Further work}

Three main areas of further research are highlighted by the evaluation of the proposed market. The issue of how best to attract and retain a critical mass of users (possibly through network effect), without which the market would not be viable, must be addressed. Further research is also needed into the questions of pricing of the use of proxy measures.

There is also a need for the development of a more detailed and technically sound solution to the problem of storing, modelling and querying the information in the personal information store.

Finally, it would also be useful to analyse a PPIM through the conceptual lens of a service system [58] and to study the business model inherent in a proposed PPIM.

\section{References}

[1] R. Farrelly and E. Chew, "Towards a Primary Personal Information Market”. Twelfth International Conference on Technology, Knowledge, and Society, Forthcoming.

[2] C. Rees, "Who owns our data?". Computer Law \& Security Review, 2014. 30(1): p. 75-79.

[3] T. Dalgic and M. Leeuw, "Niche Marketing Revisited: Concept, Applications and Some European Cases". European Journal of Marketing, 1994. 28(4): p. $39-55$.

[4] S. Searby, "Personalisation-an overview of its use and potential”. BT Technology Journal, 2003. 21(1): p. 13-19.

[5] J. Rose, O. Rehse and B. Röber, "The value of our digital identity". Boston Cons. Gr, 2012.

[6] S. Spiekermann and A. Novotny, "The Vision: Personal Information Markets AND Privacy”. 2014.

[7] S. Conger, J.H. Pratt and K.D. Loch, "Personal information privacy and emerging technologies". Information Systems Journal, 2013. 23(5): p. 401-417.

[8] K. Peffers, T. Tuunanen, C.E. Gengler, M. Rossi, W. Hui, V. Virtanen and J. Bragge, "The design science research process: a model for producing and presenting information systems research". Proceedings of the first international conference on design science research in information systems and technology (DESRIST 2006), 2006: p. 83-106.

[9] K. Peffers, T. Tuunanen, M. Rothenberger and S. Chatterjee, "A Design Science Research Methodology for Information Systems Research". Journal of Management Information Systems, 2007-8. 24(3): p. 4577.

[10] C. Weinhardt and H. Gimpel, "Market engineering: An interdisciplinary research challenge". Negotiation and Market Engineering, 2006(06461).

[11] P. Offermann, O. Levina, M. Schönherr and U. Bub, "Outline of a Design Science Research Process". DESRIST'09, 2009.

[12] H. Liu, "On advancing business intelligence in the electricity retail market". 2014.

[13] S. Dunnebeil, A. Sunyaev, J.M. Leimeister and H. Krcmar, "Market engineering for electronic health 
services". System Science (HICSS), 2012 45th Hawaii International Conference on, 2012: p. 952-961.

[14] B. Schnizler, D. Neumann and C. Weinhardt, "Resource allocation in computational grids - a market engineering approach". Proceedings of the WeB 2004, Washington, 2004: p. 19-31.

[15] T. Wu. Facebook Should Pay All of Us. 2015 [accessed 2015 22/08/2015]; Available from: http://www.newyorker.com/business/currency/facebookshould-pay-all-of-us.

[16] B. Kitchenham, O.P. Brereton, D. Budgen, M. Turner, J. Bailey and S. Linkman, "Systematic literature reviews in software engineering-a systematic literature review". Information and Software Technology, 2009. 51(1): p. 7-15.

[17] Negotiation, Auctions, and Market Engineering, $\mathrm{H}$. Gimpel, Jennings, N.R., Kersten, G.E., Ockenfels, A., Weinhardt, C., Editor. 2006, Springer.

[18] A.E. Roth, "What Have We Learned from Market Design?". NBER Innovation Policy \& the Economy (University of Chicago Press), 2008. 9: p. 79-112.

[19] A. Mashhadi, F. Kawsar and U.G. Acer, "Human Data Interaction in IoT: The ownership aspect". Internet of Things (WF-IoT), 2014 IEEE World Forum on, 2014: p. $159-162$.

[20] T. Hoeren, "Big data and the ownership in data: recent developments in Europe". European Intellectual Property Review, 2014. 36(12): p. 751-754.

[21] M. Schunter, "Data Security and Privacy in 2025?". Secure Data Management, 2014: p. 37-41.

[22] K. Nissim, S. Vadhan and D. Xiao, "Redrawing the boundaries on purchasing data from privacy-sensitive individuals". Proceedings of the 5th conference on Innovations in theoretical computer science, 2014: p. 411-422.

[23] I. Li, Y. Medynskiy, J. Froehlich and J. Larsen, "Personal informatics in practice: improving quality of life through data". CHI '12 Extended Abstracts on Human Factors in Computing Systems, 2012: p. 27992802.

[24] I. Li, A. Dey and J. Forlizzi, "A stage-based model of personal informatics systems". Proceedings of the SIGCHI Conference on Human Factors in Computing Systems, 2010: p. 557-566.

[25] A. Shimojo, S. Kamada, S. Matsumoto and M. Nakamura, "On integrating heterogeneous lifelog services". Proceedings of the 12th International Conference on Information Integration and Web-based Applications \& Services, 2010: p. 263-272.

[26] D. Kyriacou and H.C. Davis, "Moving Towards Life-Long User Modeling”. Advanced Learning Technologies, 2008. ICALT '08. Eighth IEEE International Conference on, 2008: p. 647-648.
[27] M. Thapliyal, H.L. Mandoria and N. Garg, "Data Security Analysis in Cloud Environment: A Review". 2014.

[28] M. Sugumaran, B.B. Murugan and D. Kamalraj, "An Architecture for Data Security in Cloud Computing". Computing and Communication Technologies (WCCCT), 2014 World Congress on, 2014: p. 252-255.

[29] S. Milyaeva and D. Neyland, "On re-devising markets, re-locating value: Online personal data and 'empowering'privacy". Forthcoming.

[30] S. Wang, S. Zheng, L. Xu, D. Li and H. Meng, “A literature review of electronic marketplace research: Themes, theories and an integrative framework". Information Systems Frontiers, 2008. 10(5): p. 555-571.

[31] S. Spiekermann and A. Novotny, "A vision for global privacy bridges: technical and legal measures for international data markets". Computer Law \& Security Review, 2015. 31(2): p. 181-200.

[32] C. Aperjis and B. Huberman, "A Market for Unbiased Private Data: Paying Individuals According to their Privacy Attitudes". 2012.

[33] Y.A. de Montjoye, E. Shmueli, S.S. Wang and A.S. Pentland, "openPDS: Protecting the Privacy of Metadata through SafeAnswers". PloS one, 2014. 9(7): p. e98790.

[34] Y.A. de Montjoye, S.S. Wang, A. Pentland, D.T.T. Anh and A. Datta, "On the Trusted Use of Large-Scale Personal Data". IEEE Data Eng. Bull., 2012. 35(4): p. 58.

[35] F. Zannier. A bite of Me. 2013 28th Oct, 2013 [accessed 2015 20th April]; Available from: https://www.kickstarter.com/projects/1461902402/a-bite-of-me.

[36] S. Sevignani, "The commodification of privacy on the Internet". Science and Public Policy, 2013. 40(6): p. 733-739.

[37] A. Hevner, S. March, J. Park and S. Ram, "Design Science in Information Systems Research". MIS Quarterly, 2004. 28(1): p. 75-105.

[38] C. Weinhardt, C. Holtmann and D. Neumann, "Market-engineering". Wirtschaftsinformatik, 2003. 45(6): p. 635-640.

[39] R.K. Yin, Case study research: Design and methods. 2013: Sage publications.

[40] A. Karunakaran and S. Purao, "Designing for recombination: process design through template combination", in Design Science Research in Information Systems. Advances in Theory and Practice. 2012, Springer. p. 36-51.

[41] A. Knol, H. Sol and J. Van Wamelen, Decision enhancement for sourcing with shared service centres in 
the Dutch government, in Design Science Research in Information Systems. Advances in Theory and Practice. 2012, Springer. p. 239-255.

[42] K.M. Eisenhardt, "Building theories from case study research". Academy of management review, 1989. 14(4): p. $532-550$.

[43] H. Merkens, "Selection Procedures, Sampling, Case Construction". A companion to qualitative research, 2004: p. 165-171.

[44] N. King, "Qualitative methods in organizational research: A practical guide". The Qualitative Research Interview, 1994.

[45] N. Granados, A. Gupta and R.J. Kauffman, "Identifying facilitators and inhibitors of market structure change: a hybrid theory of unbiased electronic markets". System Sciences, 2005. HICSS'05. Proceedings of the 38th Annual Hawaii International Conference on, 2005: p. $161 \mathrm{c}-161 \mathrm{c}$.

[46] P. Milgrom, "Critical Issues in the Practice of Market Design”. Economic Inquiry, 2011. 49(2): p. 313.

[47] P. Schwartz, "Property, Privacy, and Personal Data". Harvard Law Revew, 2003. 115: p. 2056.

[48] Facebook. Statement of Rights and Responsibilities. 2014 [accessed 2014 12th November]; Available from: https://www.facebook.com/legal/terms.

[49] Twitter. Terms of Service. 2014 [accessed 2014 12th November]; Available from: https://twitter.com/tos.

[50] Linkedin. User Agreement. 2014 [accessed 2014 12th November]; Available from: https://www.linkedin.com/legal/user-agreement.
[51] J. Wiese, "Enabling an ecosystem of personal behavioral data". Proceedings of the adjunct publication of the 26th annual ACM symposium on User interface software and technology, 2013: p. 41-44.

[52] R. Rawassizadeh, M. Tomitsch, K. Wac and A.M. Tjoa, "UbiqLog: a generic mobile phone-based life-log framework". Personal and Ubiquitous Computing, 2013. 17(4): p. 621-637.

[53] R. Albatal, C. Gurrin, Z. Jiang, Y. Yang, D. Carthy and L. Na, "Senseseer mobile-cloud-based Lifelogging framework". Technology and Society (ISTAS), 2013 IEEE International Symposium on, 2013: p. 144-146.

[54] L. Sweeney, "k-anonymity: A model for protecting privacy". International Journal of Uncertainty, Fuzziness and Knowledge-Based Systems, 2002. 10(05): p. 557570 .

[55] N. Li, T. Li and S. Venkatasubramanian, "Closeness: A new privacy measure for data publishing". Knowledge and Data Engineering, IEEE Transactions on, 2010. 22(7): p. 943-956.

[56] A. Machanavajjhala, D. Kifer, J. Gehrke and M. Venkitasubramaniam, "l-diversity: Privacy beyond kanonymity". ACM Transactions on Knowledge Discovery from Data (TKDD), 2007. 1(1): p. 3.

[57] Y.A. de Montjoye, C.A. Hidalgo, M. Verleysen and V.D. Blondel, "Unique in the Crowd: The privacy bounds of human mobility". Scientific reports, 2013.3.

[58] P.P. Maglio and J. Spohrer, "A service science perspective on business model innovation". Industrial Marketing Management, 2013. 42(5): p. 665-670. 